\title{
MODELING THE LUKEWARM CORINO PHASE: IS L1527 UNIQUE?
}

\author{
George E. Hassel \\ Department of Physics, The Ohio State University, Columbus, OH 43210; ghassel@mps.ohio-state.edu \\ ERIC Herbst \\ Departments of Physics, Astronomy, and Chemistry, The Ohio State University, Columbus, OH 43210 \\ AND \\ RoBIN T. GARROD \\ Max-Planck-Institut für Radioastronomie, Auf dem Hügel 69, 53121 Bonn, Germany \\ Received 2008 January 25; accepted 2008 March 11
}

\begin{abstract}
Sakai et al. have observed long-chain unsaturated hydrocarbons and cyanopolyynes in the low-mass star-forming region L1527, and have attributed this result to a gas-phase ion-molecule chemistry, termed warm carbon-chain chemistry, which occurs during and after the evaporation of methane from warming grains. The source L1527 is an envelope surrounding a Class $0 / \mathrm{I}$ protostar with regions that possess a slightly elevated temperature of $\approx 30 \mathrm{~K}$. The molecules detected by Sakai et al. are typically associated only with dark molecular clouds, and not with the more evolved hot corino phase. In order to determine whether L1527 is chemically distinct from a dark cloud, we compute models including various degrees of heating. The results indicate that the composition of L1527 is somewhat more likely to be due to warm carbon-chain chemistry than to be a remnant of a colder phase. If so, the molecular products provide a signature of a previously uncharacterized early phase of low-mass star formation, which can be characterized as a "lukewarm" corino. We also include predictions for other molecular species that might be observed toward candidate lukewarm corino sources. Although our calculations show that unsaturated hydrocarbons and cyanopolyynes can be produced in the gas phase as the grains warm up to $30 \mathrm{~K}$, they also show that such species do not disappear rapidly from the gas as the temperature reaches $200 \mathrm{~K}$, implying that such species might be detected in hot corinos and hot cores.
\end{abstract}

Subject headings: ISM: individual (L1527) — ISM: molecules — stars: formation

\section{INTRODUCTION}

Recent observations by Sakai et al. (2008b; hereafter SS08) of the warm gas associated with L1527 have revealed an unexpected chemical composition including unsaturated chain radicals of formula $\mathrm{C}_{n} \mathrm{H}$, carbenes of formula $\mathrm{C}_{n} \mathrm{H}_{2}$, and cyanopolyynes, $\mathrm{HC}_{2 n} \mathrm{CN}$. These molecules are typically associated with the cold, dark cloud stage of star formation (Suzuki et al. 1992; Markwick et al. 2000; Hirota et al. 2004; Smith et al. 2004), but independent observations indicate that the physical state of L1527 is more dense and slightly warmer than dark clouds. Indeed, the column densities of 13 species detected by SS08 toward L1527 are only slightly lower than those detected toward the dark cloud TMC-1. The presence of such unsaturated species indicates that L1527 may be one example of a chemically unexplored, transitional phase of low-mass star formation. The analogy with dark clouds is strengthened by the detection of the anions $\mathrm{C}_{6} \mathrm{H}^{-}$(Sakai et al. 2007) and, most recently, $\mathrm{C}_{4} \mathrm{H}^{-}$(Sakai et al. 2008c; Agúndez et al. 2008).

The physical structure of L1527 contains an envelope surrounding the low-mass protostar IRAS $04368+2557$ with the object between the Class 0 and I protostellar phases (André et al. 2000). According to Myers \& Mardones (1998) the envelope is undergoing inside-out collapse in good agreement with the Shu (1977) model. The source also shows evidence for bipolar outflows in the plane of the sky (Ohashi et al. 1997). The SS08 observations include a description of a profile mapping technique, indicating that the velocity of $\mathrm{C}_{4} \mathrm{H}$ is consistent with the central protostar rather than the outflow region. This region differs from previously investigated star formation phases because the en- velope is only slightly elevated in temperature. Based on a fit to central peak emission and the spectral energy distribution (SED), Hogerheijde \& Sandell (2000) determined a temperature of $35 \mathrm{~K}$, while Loinard et al. (2002) obtained a temperature of $22 \mathrm{~K}$ via a similar computation for the central region of L1527. These temperatures are slightly warmer than a typical $10 \mathrm{~K}$ cold cloud but colder than a hot core/corino region. Selected temperatures in these evolved regions have been estimated as $T=50-80 \mathrm{~K}$ for the low-mass hot corinos in NGC 1333 (Maret et al. 2004), $T>$ $100 \mathrm{~K}$ for the IRAS 16293 hot corino (Ceccarelli et al. 2000), and $T=150-200 \mathrm{~K}$ for the G327.3-0.6 high-mass hot core (Gibb et al. 2000). In addition to observations of its physical state, L1527 was included among 18 dense cores in the molecular survey of Jørgensen et al. (2004; hereafter JSV04). These authors detected the molecular species $\mathrm{CO}, \mathrm{CN}, \mathrm{CS}, \mathrm{HCN}, \mathrm{HNC}, \mathrm{HC}_{3} \mathrm{~N}$, $\mathrm{SO}, \mathrm{HCO}^{+}$, and $\mathrm{N}_{2} \mathrm{H}^{+}$toward $\mathrm{L} 1527$. Although this set of observations does not include hydrocarbons or complex cyanopolyynes and does not include velocity variations, it does provide an independent basis for model comparison. It is clear that further interferometric study of L1527 will provide much more information toward understanding the nature of this source.

While the presence of nonsaturated hydrocarbons is more typically a dark cloud characteristic, the hot core/corino evolutionary phases are more commonly associated with more saturated, oxygen- and nitrogen-rich species. What can explain the darkcloud species detected in L1527? One possibility is that these molecules are merely remnants of the colder prestellar core phase that survive a very fast collapse toward the center of the object. In the dense portions of such sources, however, it is expected that the carbon chain molecules would freeze out onto grain surfaces more 
TABLE 1

Granular Properties

\begin{tabular}{|c|c|c|}
\hline Parameter & Symbol & Value \\
\hline 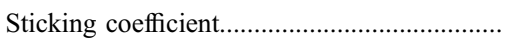 & $S$ & 0.5 \\
\hline Radius $(\mu \mathrm{m})$ & $a$ & 0.1 \\
\hline 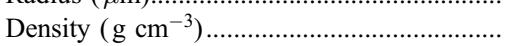 & $\rho$ & 3 \\
\hline 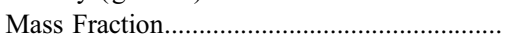 & $X_{d}$ & 0.01 \\
\hline Reactive Desorption Efficiency ....................... & $a_{\mathrm{RRK}}$ & 0.01 \\
\hline
\end{tabular}

rapidly than in a cloud of lower density. As noted in SS08, the slight elevation in temperature is capable of regenerating abundances of carbon-chain molecules after they have frozen out to grain surfaces. The mechanism for this process is more likely the selective release and subsequent reaction of highly volatile molecules such as methane $\left(\mathrm{CH}_{4}\right)$ from grain surfaces than the actual sublimation of carbon chains formed by cold processes. For this reason, the process was named warm carbon-chain chemistry, or WCCC (SS08).

In this paper, we present detailed models of a low-mass starforming region with a slightly elevated temperature, for which we use the phrase "lukewarm corino," where the adjective "lukewarm" was previously used in talks by E. van Dishoeck. Specifically, we attempt to determine whether the observations can be explained by models of a cold region alone, or whether the chemistry is the signature of a newly discovered protostellar phase that requires only a small amount of heating. In particular, we consider models in which a cold dense phase is followed by a warming to temperatures of $30 \mathrm{~K}$ and beyond, based both on the dust warming and on molecular line observations (SS08). The method used is similar to that discussed by Garrod \& Herbst (2006) for hot cores and corinos, in which a gas-grain chemical model is utilized and both surface and gas-phase reactions are considered during the cold and heat-up phases. If L1527 is a representative example of a simple, isolated, collapsing core, perhaps more low-mass protostellar sources should exhibit a similar lukewarm envelope and the WCCC chemical signature.

\section{MODEL}

We utilize the Ohio State University (OSU) gas-grain code, first described by Hasegawa et al. (1992) with some more recent modifications, the most important of which is the capability to increase gas and dust temperatures with time (Garrod \& Herbst 2006). The model includes the granular parameters listed in Table 1. We include the Rice-Ramsperger-Kessel (RRK) approach for reactive desorption from the solid phase, first suggested by Garrod et al. (2006). Reactive desorption, or nonthermal desorption of the products of exothermic surface reactions, is regulated by the parameter $a_{\mathrm{RRK}}$, approximately equal to the efficiency of the process. For the models reported here $a_{\mathrm{RRK}}=0.01$, as chosen by Garrod et al. (2007). The results of corresponding models with $a_{\text {RRK }}=0$ are not significantly different from those presented, and are thus omitted for simplicity. In addition to the previously published modifications of the gas-grain network, we added the photodesorption of $\mathrm{CO}$ ice, based on the laboratory measurements of Öberg et al. (2007). The desorption can be caused by both the ambient UV field and by secondary photons generated by cosmic rays. Because L1527 is a dense region, and not UV dominated, we assume a typical interstellar radiation field and a value $A_{\mathrm{v}}=10$ for all models presented. Consequently, the inclusion of $\mathrm{CO}$ photodesorption does not introduce a significant departure from results in which it is not included. The network includes 6312 reactions involving a total of 655 gaseous and
TABLE 2

INITIAL AbUNDANCES

\begin{tabular}{|c|c|}
\hline Species $i$ & $n_{i} / n_{\mathrm{H}}^{\mathrm{a}}$ \\
\hline $\mathrm{H}_{2}$ & 0.5 \\
\hline 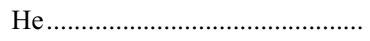 & 0.14 \\
\hline $\mathrm{C}^{+}$ & $7.3(-5)$ \\
\hline $\mathrm{N}$ & $2.14(-5)$ \\
\hline 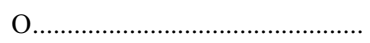 & $1.76(-4)$ \\
\hline 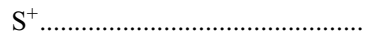 & $8.0(-8)^{b}$ \\
\hline $\mathrm{Na}^{+}$ & $2.0(-9)$ \\
\hline $\mathrm{Mg}^{+}$ & $7.0(-9)$ \\
\hline $\mathrm{Si}^{+} \ldots \ldots+\ldots$ & $8.0(-9)$ \\
\hline $\mathrm{P}^{+}$ & $3.0(-9)$ \\
\hline $\mathrm{Cl}^{+}$ & $4.0(-9)$ \\
\hline $\mathrm{Fe}^{+}$ & $3.0(-9)$ \\
\hline
\end{tabular}

surface species. Negative molecular ions have not yet been included in the model; an explanation of their abundances in L1527 is being undertaken using a purely gas-phase model.

Our overall method is to follow the chemical evolution of a homogeneous (one-point) parcel of material as it progresses through the cold prestellar core phase and then heats up. It is assumed that the dust and gas temperatures are in equilibrium with one another. This approach differs from the hydrodynamic multipoint collapse model of Aikawa et al. (2008) in that we make simplified estimates of the time dependence and final value of the temperature and focus on the details of chemical evolution of groups of molecules during both the cold and warming-up phases. The advantage of our approach is that we are not wedded to a particular dynamical time dependence; the disadvantage is that it is unclear whether the physical changes that occur are totally realistic.

We start the calculations by simulating the gas-grain chemistry that occurs in the central region of a cold prestellar core with a constant density of $n_{\mathrm{H}}=10^{6} \mathrm{~cm}^{-3}$ and an initial temperature of $T=10 \mathrm{~K}$. We start with gaseous atoms and ions except for molecular hydrogen, with abundances following low-metal elemental abundances as listed in Table 2 (Garrod et al. 2007). In addition, we consider the effect of an increased sulfur abundance of $1 \times 10^{-5}$, initially in the form of $\mathrm{S}^{+}$, and we discuss the results of this variation below. Figure 1 shows the fractional abundances

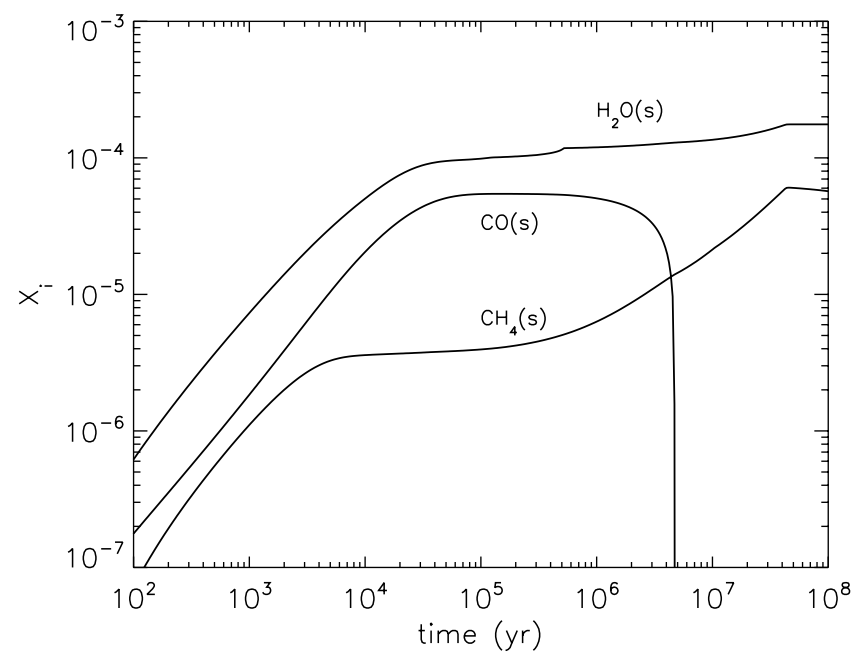

FIG. 1.- Surface fractional abundances of major mantle species with respect to total hydrogen at $n_{\mathrm{H}}=10^{6} \mathrm{~cm}^{-3}$ and $T=10 \mathrm{~K}$. 
of the major ice species $\mathrm{H}_{2} \mathrm{O}(\mathrm{s}), \mathrm{CO}(\mathrm{s})$, and $\mathrm{CH}_{4}(\mathrm{~s})$ as functions of time under these conditions. The surface abundance of the predominant component, $\mathrm{H}_{2} \mathrm{O}(\mathrm{s})$, reaches a steady state fractional abundance of $\approx 10^{-4}$ after a little more than $10^{4} \mathrm{yr}$, while both $\mathrm{CH}_{4}(\mathrm{~s})$ and $\mathrm{CO}(\mathrm{s})$ reach a quasi-steady state at this time. After $10^{6} \mathrm{yr}, \mathrm{CO}(\mathrm{s})$ decreases dramatically because it is hydrogenated, while $\mathrm{CH}_{4}(\mathrm{~s})$ actually increases in abundance. The initial cold phase in our warm-up models is allowed to continue for $10^{5} \mathrm{yr}$, corresponding to the maximum $\mathrm{CO}(\mathrm{s})$ abundance, but we also run models to $10^{4}$ and $10^{6} \mathrm{yr}$ for comparison. The abundance of $\mathrm{CH}_{4}$ (s) in this range with respect to $\mathrm{H}_{2} \mathrm{O}(\mathrm{s})$ is calculated to be $\approx 3.5 \%$, which is in agreement with recent Spitzer Space Telescope observations according to SS08, and with previous Infrared Space Observatory (ISO) results of $1 \%-4 \%$ reported by Gibb et al. (2004). More recently, Öberg et al. (2008) reported that the $\mathrm{CH}_{4}(\mathrm{~s})$ abundance may vary by $2 \%-13 \%$ among a variety of sources, but that it is more narrowly defined to be $4.7 \% \pm 1.6 \%$ if $N_{\mathrm{H}_{2} \mathrm{O}(\mathrm{s})}>2 \times 10^{18} \mathrm{~cm}^{-2}$. Our calculation is in strong agreement with this new result. This extent of variation does not strongly affect the resulting abundances of the carbon-chain molecules to the best of our estimation. However, we cannot easily vary the amount of solid methane in our gas-grain model, since it is determined by the chemical history of the cold stage. In a gas-phase model in preparation (N. Harada \& E. Herbst), we are looking into the dependence of assorted abundances on the gas-phase abundance of methane immediately after evaporation.

After the initial cold phase, the gas and dust temperatures are increased using the expression (Garrod \& Herbst 2006)

$$
T=T_{0}+\left(T_{\max }-T_{0}\right)\left(\frac{\Delta t}{t_{h}}\right)^{n},
$$

where $T_{0}$ is the initial temperature of $10 \mathrm{~K}, T_{\max }$ is the maximum temperature, $t_{h}$ is the heating timescale, and $n$ is the order of the heating. If L1527 is in a transitional evolutionary stage between cold and hot phases, the temperature may be increasing above $30 \mathrm{~K}$. To account for this, the simulated temperature increase is carried to three maximum temperature values of $T_{\max }=30,100$, or $200 \mathrm{~K}$ in separate model runs. After reaching the asymptotic maximum, the model holds the temperature at that constant value while continuing to trace the chemical evolution. The adopted heating timescale is $2 \times 10^{5} \mathrm{yr}$ with an order of $n=2$ for each $T_{\max }$, based on the estimated warm-up timescale for intermediate star formation. Garrod \& Herbst (2006) primarily utilized this timescale to simulate the chemistry during the formation of hot cores.

\section{RESULTS}

Our results are obtained as fractional abundances with respect to $n_{\mathrm{H}}, X_{i}=n_{i} / n_{\mathrm{H}}$. The SS08 observations were reported as column densities, so comparison with observation requires us to convert these using the total hydrogen column density $N_{\mathrm{H}}=$ $6 \times 10^{22} \mathrm{~cm}^{-2}$ (Jørgensen et al. 2002). The converted observational values are listed in Table 3 along with the observed fractional abundances from the earlier study of Jørgensen et al. (2004) and presented where appropriate in figures discussed below. The results of our simulations can be plotted as temporal evolutions of molecular abundances, both in the gas and on granular surfaces, both during the cold initial period and the subsequent warm up, if it occurs. Two representative examples for unsaturated carbon chain gaseous species are shown in Figure 2, for $\mathrm{C}_{4} \mathrm{H}$, and Figure 3 , for $\mathrm{HC}_{5} \mathrm{~N}$. In these figures, we display the results for constant temperature, $T=10 \mathrm{~K}$, and for heating to $T_{\max }=30$ and $200 \mathrm{~K}$. Models with similar heating but without surface reactions are also shown, but they do not show any significant distinction among temperature variations. These example plots also include the SS08 observations as solid horizontal lines and the temperature profiles of the warm-up models. The heating onset time was chosen to be $10^{5} \mathrm{yr}$, as discussed above. Similar procedures that varied the heating onset time between $10^{4}$ and $10^{6}$ yr showed no substantial difference in the results as a function of time after the start of heat-up.

The dominant features for $\mathrm{C}_{4} \mathrm{H}$ and $\mathrm{HC}_{5} \mathrm{~N}$ in models in which heating begins to occur after $10^{5} \mathrm{yr}$ include (1) a "cold" peak at $10^{4}-10^{5} \mathrm{yr}$, which is essentially the "early-time" peak of cold gas-phase models, followed by a decrease due both to gas-phase reactions and accretion onto dust particles; (2) an increase in abundance that occurs when volatile molecules such as methane and carbon monoxide begin to sublimate from the grain surfaces as the temperature nears $30 \mathrm{~K}$; (3) a second, or warm, peak, possibly with fine structure, which occurs in the time frame $10^{5}-$ $10^{6} \mathrm{yr}$; and (4) a final decrease in abundance. The second peak occurs at or near the period when the maximum temperature in the model $(30$ or $200 \mathrm{~K})$ is reached. The warm peak abundance for $\mathrm{C}_{4} \mathrm{H}$ and $\mathrm{HC}_{5} \mathrm{~N}$ is larger for the higher temperature model; in addition, the abundances when the higher temperature model is temporarily at $30 \mathrm{~K}$ are very similar to the abundances achieved when the $30 \mathrm{~K}$ warm-up model reaches its asymptotic temperature. In the case where $T_{\max }=200 \mathrm{~K}$, a satellite warm-up peak occurs near $T=30 \mathrm{~K}$ and has abundance similar to that of the single $T_{\max }=30 \mathrm{~K}$ warm-up peak. The second, larger peak occurs when the temperature first reaches $200 \mathrm{~K}$ and the majority of the ice mantle species are driven from the grains.

In the cold model, the abundances of $\mathrm{C}_{4} \mathrm{H}$ and $\mathrm{HC}_{5} \mathrm{~N}$ are slightly regenerated in a plateau region from $t \approx 6 \times 10^{5}$ yr until $t \approx 4 \times 10^{6} \mathrm{yr}$ as a result of reactive desorption. Actually, the regenerated abundances of most molecules do not exceed the initial cold peak, with the exceptions of $\mathrm{C}_{10}, \mathrm{C}_{5} \mathrm{~N}, \mathrm{CS}, \mathrm{H}_{2} \mathrm{CS}$, and $\mathrm{H}_{2} \mathrm{~S}$. The species $\mathrm{CN}$ and $\mathrm{HCO}^{+}$do not decrease from the initial cold peak but remain at a plateau value for nearly $8 \times 10^{6} \mathrm{yr}$. Finally, as exemplified by $\mathrm{C}_{4} \mathrm{H}$ and $\mathrm{HC}_{5} \mathrm{~N}$, the warm up in the absence of surface chemistry shows no warm peak, demonstrating that surface chemistry prior to warm up is indeed necessary for the production of gas-phase molecules in the vicinity of $30 \mathrm{~K}$. The detailed mechanism for the production of the gas-phase molecules during the warm up is discussed below.

In Table 3 we list peak abundances for a large number of species for four models in addition to observed fractional abundances for $\mathrm{L} 1527$ if available. There are three columns that specify maximum asymptotic temperatures of 30,100 , and $200 \mathrm{~K}$. Here the peak values refer always to those achieved during warm up after $t=10^{5} \mathrm{yr}$ and not in the cold phase. In models with an asymptotic temperature that exceeds $30 \mathrm{~K}$, the peak values can be greater than values in the vicinity of $30 \mathrm{~K}$, as is the case for most unsaturated carbon chain species (e.g., $\mathrm{C}_{4} \mathrm{H}$ and $\mathrm{HC}_{5} \mathrm{~N}$ ), as well as all standard hot-core-type molecules. The potentially controversial high-temperature results for the unsaturated species are discussed in $\S 3.3$. In the column that lists results from a model with a constant temperature of $10 \mathrm{~K}$, the peak abundances are the cold, "early-time" values prior to $t=10^{5} \mathrm{yr}$. One can see that for unsaturated classes of organic molecules, such as the radicals $\mathrm{C}_{n} \mathrm{H}$, and the cyanopolyynes $\mathrm{HC}_{2 n} \mathrm{CN}$, the peak abundances during the warming up periods are larger than for the cold period. On the other hand, for other classes of species (e.g., molecular ions) the issue is less clear. 
TABLE 3

L1527 and Peak Calculated Fractional Abundances of Assorted Species

\begin{tabular}{|c|c|c|c|c|c|}
\hline Species & Observed Fractional Abundance & $T=10 \mathrm{~K}$ & $T_{\max }=30 \mathrm{~K}$ & $T_{\max }=100 \mathrm{~K}$ & $T_{\max }=200 \mathrm{~K}$ \\
\hline 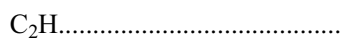 & $8.3(-09)^{\mathrm{a}}$ & $2.0(-09)$ & $8.9(-09)$ & $1.0(-08)$ & $1.1(-08)$ \\
\hline 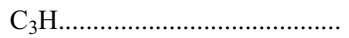 & $\ldots$ & $5.0(-10)$ & $1.9(-09)$ & $1.2(-08)$ & $1.5(-08)$ \\
\hline 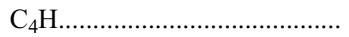 & $3.3(-09)^{\mathrm{a}}$ & $1.8(-10)$ & $3.0(-09)$ & $3.3(-08)$ & $4.1(-08)$ \\
\hline 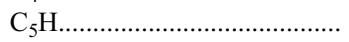 & $1.6(-11)^{\mathrm{a}}$ & $1.2(-11)$ & $8.7(-10)$ & $8.1(-09)$ & $2.9(-08)$ \\
\hline 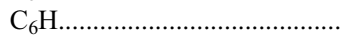 & $1.0(-11)^{\mathrm{a}}$ & $1.5(-11)$ & $6.0(-10)$ & $5.8(-09)$ & $3.5(-08)$ \\
\hline 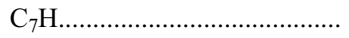 & $\ldots$ & $9.3(-13)$ & $4.4(-10)$ & $2.7(-09)$ & $3.6(-08)$ \\
\hline 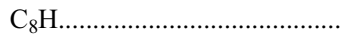 & $\ldots$ & $1.2(-12)$ & $7.2(-10)$ & $3.1(-09)$ & $3.1(-08)$ \\
\hline $\mathrm{C}_{9} \mathrm{H} \ldots \ldots \ldots \ldots \ldots . . . . . . .$. & $\ldots$ & $4.8(-14)$ & $5.1(-10)$ & $2.4(-09)$ & $3.4(-08)$ \\
\hline $\mathrm{HC}_{5} \mathrm{~N}$ & $9.7(-11)^{\mathrm{a}}$ & $9.1(-11)$ & $5.4(-10)$ & $5.1(-08)$ & $2.0(-07)$ \\
\hline 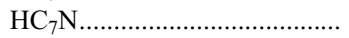 & $2.7(-11)^{\mathrm{a}}$ & $4.3(-12)$ & $1.9(-10)$ & $6.3(-09)$ & $4.1(-08)$ \\
\hline 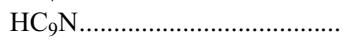 & $2.5(-12)^{\mathrm{a}}$ & $1.5(-13)$ & $9.9(-11)$ & $1.7(-09)$ & $1.7(-08)$ \\
\hline 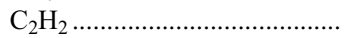 & $\ldots$ & $6.5(-09)$ & $4.2(-08)$ & $1.6(-07)$ & $2.3(-07)$ \\
\hline 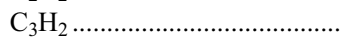 & $1.0(-11)^{\mathrm{a}}$ & $9.5(-13)^{b}$ & $1.8(-11)^{\mathrm{b}}$ & $4.8(-10)^{\mathrm{b}}$ & $4.7(-10)^{\mathrm{b}}$ \\
\hline 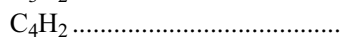 & $2.2(-11)^{\mathrm{a}}$ & $2.9(-12)^{b}$ & $1.7(-10)^{\mathrm{b}}$ & $1.4(-09)^{b}$ & $2.2(-09)^{\mathrm{b}}$ \\
\hline 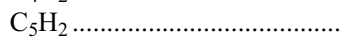 & $\ldots$ & $1.4(-13)^{\mathrm{b}}$ & $4.8(-11)^{\mathrm{b}}$ & $1.3(-09)^{\mathrm{b}}$ & $1.4(-09)^{\mathrm{b}}$ \\
\hline $\mathrm{C}_{6} \mathrm{H}_{2} \ldots \ldots \ldots \ldots \ldots \ldots \ldots \ldots \ldots \ldots \ldots \ldots \ldots \ldots \ldots \ldots \ldots \ldots$ & $2.5(-12)^{\mathrm{a}}$ & $1.2(-13)^{\mathrm{b}}$ & $6.2(-11)^{\mathrm{b}}$ & $2.0(-10)^{\mathrm{b}}$ & $1.0(-09)^{\mathrm{b}}$ \\
\hline 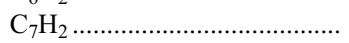 & $\ldots$ & $9.9(-15)^{b}$ & $2.1(-11)^{\mathrm{b}}$ & $1.4(-10)^{\mathrm{b}}$ & $6.0(-10)^{b}$ \\
\hline 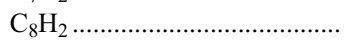 & $\ldots$ & $8.7(-15)^{b}$ & $3.0(-11)^{\mathrm{b}}$ & $7.1(-11)^{b}$ & $4.0(-10)^{b}$ \\
\hline 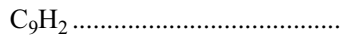 & $\ldots$ & $5.9(-16)^{\mathrm{b}}$ & $2.0(-11)^{\mathrm{b}}$ & $9.7(-11)^{\mathrm{b}}$ & $1.1(-09)^{\mathrm{b}}$ \\
\hline $\mathrm{CH}_{3} \mathrm{CCH}$ & $7.8(-10)^{\mathrm{a}}$ & $2.4(-10)$ & $4.0(-09)$ & $9.6(-07)$ & $9.3(-07)$ \\
\hline 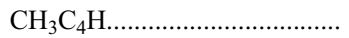 & $\ldots$ & $2.0(-12)$ & $2.3(-09)$ & $7.2(-09)$ & $5.9(-08)$ \\
\hline 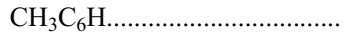 & $\ldots$ & $3.1(-13)$ & $5.8(-10)$ & $2.1(-09)$ & $7.6(-09)$ \\
\hline $\mathrm{CCS}$ & $8.5(-11)^{\mathrm{a}}$ & $2.0(-10)$ & $1.3(-10)$ & $1.2(-09)$ & $1.1(-09)$ \\
\hline 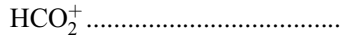 & $1.0(-12)^{\mathrm{c}}$ & $1.6(-12)$ & $7.8(-13)$ & $2.4(-11)$ & $3.8(-12)$ \\
\hline $\mathrm{HCN}$ & $1.2(-09)^{\mathrm{d}}$ & $2.1(-07)$ & $6.9(-09)$ & $1.7(-06)$ & $1.8(-06)$ \\
\hline 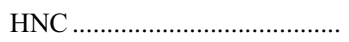 & $3.2(-10)^{\mathrm{d}}$ & $1.4(-07)$ & $5.6(-09)$ & $7.7(-07)$ & $1.2(-06)$ \\
\hline $\mathrm{HC}_{3} \mathrm{~N}$ & $8.9(-10)^{\mathrm{d}}$ & $3.1(-09)$ & $8.8(-10)$ & $1.2(-07)$ & $1.4(-07)$ \\
\hline $\mathrm{CO}$ & $3.9(-05)^{\mathrm{d}}$ & $3.3(-05)$ & $5.2(-05)$ & $7.3(-05)$ & $7.3(-05)$ \\
\hline $\mathrm{CS}$ & $3.3(-10)^{\mathrm{d}}$ & $6.4(-08)$ & $8.0(-09)$ & $5.7(-08)$ & $5.0(-08)$ \\
\hline $\mathrm{SO} \ldots \ldots \ldots \ldots \ldots \ldots \ldots$ & $1.4(-10)^{\mathrm{d}}$ & $1.1(-09)$ & $1.5(-10)$ & $5.6(-08)$ & $5.0(-08)$ \\
\hline $\mathrm{HCO}^{+}$ & $6.0(-10)^{\mathrm{d}}$ & $4.4(-10)$ & $1.8(-09)$ & $2.2(-09)$ & $1.8(-09)$ \\
\hline 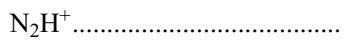 & $2.5(-10)^{\mathrm{d}}$ & $6.3(-11)$ & $6.1(-10)$ & $6.2(-11)$ & $8.1(-11)$ \\
\hline $\mathrm{CN}$ & $8.0(-11)^{\mathrm{d}}$ & $3.2(-09)$ & $4.0(-09)$ & $3.0(-07)$ & $3.0(-07)$ \\
\hline $\mathrm{C}_{2}$ & $\ldots$ & $3.4(-09)$ & $2.0(-09)$ & $4.3(-08)$ & $3.6(-08)$ \\
\hline 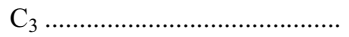 & $\ldots$ & $2.3(-06)$ & $3.9(-08)$ & $2.7(-07)$ & $2.0(-07)$ \\
\hline $\mathrm{C}_{4}$ & $\ldots$ & $8.2(-09)$ & $1.3(-09)$ & $1.2(-08)$ & $1.8(-08)$ \\
\hline 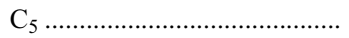 & $\ldots$ & $1.4(-08)$ & $1.5(-08)$ & $6.2(-08)$ & $2.4(-07)$ \\
\hline $\mathrm{C}_{6}$ & $\ldots$ & $6.0(-11)$ & $3.3(-09)$ & $5.3(-09)$ & $5.8(-08)$ \\
\hline $\mathrm{C}_{7}$ & $\ldots$ & $6.4(-10)$ & $7.8(-09)$ & $6.9(-09)$ & $1.7(-07)$ \\
\hline $\mathrm{C}_{8}$ & $\cdots$ & $5.8(-12)$ & $2.9(-09)$ & $2.3(-09)$ & $5.1(-08)$ \\
\hline $\mathrm{C}_{9}$ & $\ldots$ & $4.4(-11)$ & $1.4(-08)$ & $7.4(-09)$ & $2.7(-07)$ \\
\hline 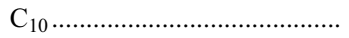 & $\ldots$ & $8.2(-14)$ & $9.4(-10)$ & $1.4(-09)$ & $1.5(-08)$ \\
\hline $\mathrm{C}_{2} \mathrm{~N}$ & $\ldots$ & $1.2(-10)$ & $8.9(-10)$ & $3.3(-08)$ & $4.5(-08)$ \\
\hline $\mathrm{C}_{3} \mathrm{~N}$ & $\ldots$ & $2.2(-11)$ & $3.0(-10)$ & $3.4(-08)$ & $3.3(-08)$ \\
\hline $\mathrm{C}_{4} \mathrm{~N}$ & $\ldots$ & $1.6(-11)$ & $9.2(-10)$ & $3.2(-08)$ & $7.2(-08)$ \\
\hline 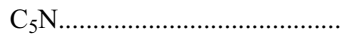 & $\ldots$ & $6.8(-13)$ & $5.6(-10)$ & $2.7(-08)$ & $6.6(-08)$ \\
\hline $\mathrm{C}_{7} \mathrm{~N}$ & $\ldots$ & $4.5(-14)$ & $2.2(-10)$ & $3.0(-09)$ & $2.0(-08)$ \\
\hline 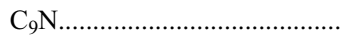 & $\ldots$ & $2.8(-15)$ & $1.1(-10)$ & $4.8(-10)$ & $7.3(-09)$ \\
\hline $\mathrm{CH}_{3} \mathrm{C}_{3} \mathrm{~N} \ldots \ldots \ldots \ldots \ldots \ldots \ldots \ldots \ldots \ldots \ldots \ldots \ldots \ldots$ & $\ldots$ & $7.5(-12)$ & $7.3(-13)$ & $1.9(-11)$ & $1.8(-10)$ \\
\hline 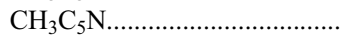 & $\ldots$ & $2.1(-13)$ & $8.8(-14)$ & $2.1(-11)$ & $2.7(-10)$ \\
\hline 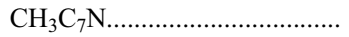 & $\ldots$ & $9.5(-15)$ & $3.2(-14)$ & $2.7(-12)$ & $3.2(-11)$ \\
\hline 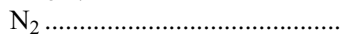 & $\ldots$ & $1.9(-06)$ & $5.6(-06)$ & $1.1(-05)$ & $1.1(-05)$ \\
\hline 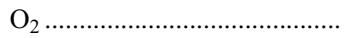 & $\ldots$ & $3.7(-07)$ & $3.7(-08)$ & $4.8(-05)$ & $4.3(-05)$ \\
\hline 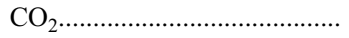 & $\ldots$ & $5.4(-07)$ & $8.6(-09)$ & $9.2(-06)$ & $1.8(-06)$ \\
\hline 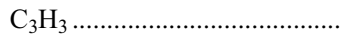 & $\ldots$ & $2.1(-10)$ & $3.9(-09)$ & $7.5(-08)$ & $8.5(-08)$ \\
\hline 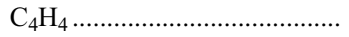 & $\cdots$ & $3.7(-11)$ & $6.1(-10)$ & $2.6(-07)$ & $2.3(-07)$ \\
\hline 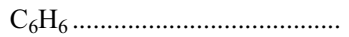 & $\ldots$ & $5.4(-13)$ & $1.6(-09)$ & $6.6(-09)$ & $1.8(-08)$ \\
\hline $\mathrm{H}_{2} \mathrm{CS}$ & $\ldots$ & $1.9(-10)$ & $5.7(-10)$ & $4.8(-08)$ & $4.6(-08)$ \\
\hline $\mathrm{H}_{2} \mathrm{~S}$ & $\ldots$ & $1.5(-09)$ & $4.7(-09)$ & $8.7(-09)$ & $7.9(-09)$ \\
\hline 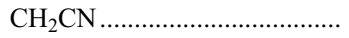 & $\ldots$ & $1.9(-10)$ & $1.0(-10)$ & $6.4(-08)$ & $8.4(-08)$ \\
\hline 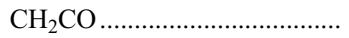 & $\ldots$ & $6.4(-09)$ & $1.0(-09)$ & $1.3(-07)$ & $1.4(-07)$ \\
\hline
\end{tabular}

${ }^{\text {a }}$ Reported in Sakai et al. (2008b).

b Calculations adjusted for carbene isomer as described in $\S 3.2$.

c Recently observed by Sakai et al. (2008a).

d Reported in Jørgensen et al. (2004). 


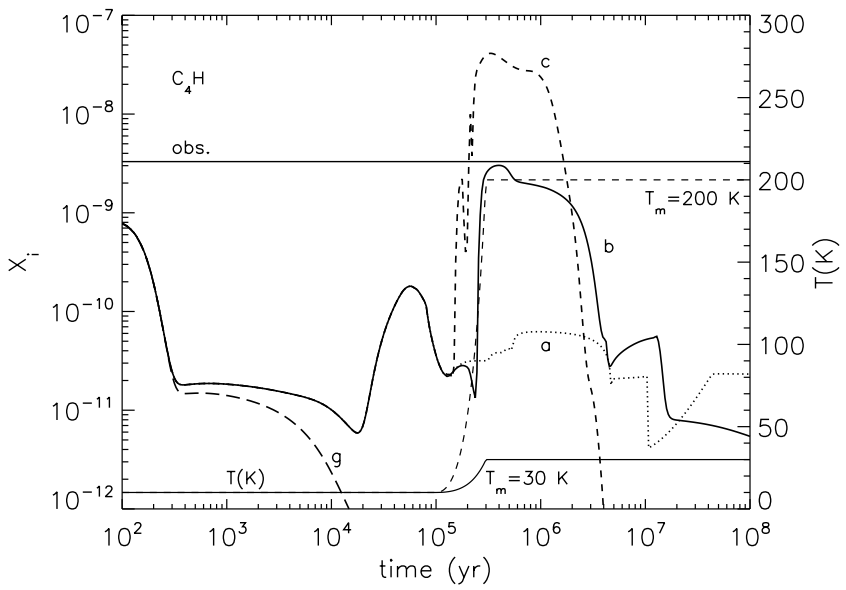

FIG. 2.-Temporal evolution of the $\mathrm{C}_{4} \mathrm{H}$ abundance. All models undergo a cold prestellar core period of $10^{5} \mathrm{yr}$. The results are computed for three temperature variations: constant $T=10 \mathrm{~K}$, labeled a; warm up to $T_{\max }=30 \mathrm{~K}$, labeled b; warm up to $T_{\max }=200 \mathrm{~K}$, labeled c. Models without grain-surface chemistry are included and labeled $\mathrm{g}$. These models overlap for all three heating variations. The temperature profile for the two warm-up models is also plotted vs. time. The observed abundance is indicated with a horizontal line.

\subsection{Chemical Interpretation}

It is desirable to understand the mechanism(s) responsible for the increase in abundance of gas-phase carbon-chain species during the warm-up period. As gas-phase species freeze out onto grains in the cold era, they are regenerated when highly volatile precursor species sublimate as the temperature approaches $\approx 30 \mathrm{~K}$ and subsequently react in the gas phase. Methane plays a key role in the formation of unsaturated hydrocarbons, so its evolution is shown in Figure 4 for models with no warm up and warm up to 30 and $200 \mathrm{~K}$. During the cold era, a large abundance of methane ice builds up in all models, formed mainly by sequential hydrogenation of carbon on surfaces, in which the concluding reaction is

$$
\mathrm{H}(\mathrm{s})+\mathrm{CH}_{3}(\mathrm{~s}) \longrightarrow \mathrm{CH}_{4}(\mathrm{~s}) \text {. }
$$

The desorption of methane that occurs as a result of heating to $30 \mathrm{~K}$ and beyond becomes apparent in the top panels of Figure 4 . As this desorption occurs, gas-phase chemistry begins to regenerate many unsaturated species. The corresponding increase in $\mathrm{C}_{4} \mathrm{H}$ abundance is evident in Figure 2 at $t \sim 3 \times 10^{5} \mathrm{yr}$ for $T_{\max }=30 \mathrm{~K}$ and $t \sim 1.5 \times 10^{5} \mathrm{yr}$ for $T_{\max }=200 \mathrm{~K}$. Models

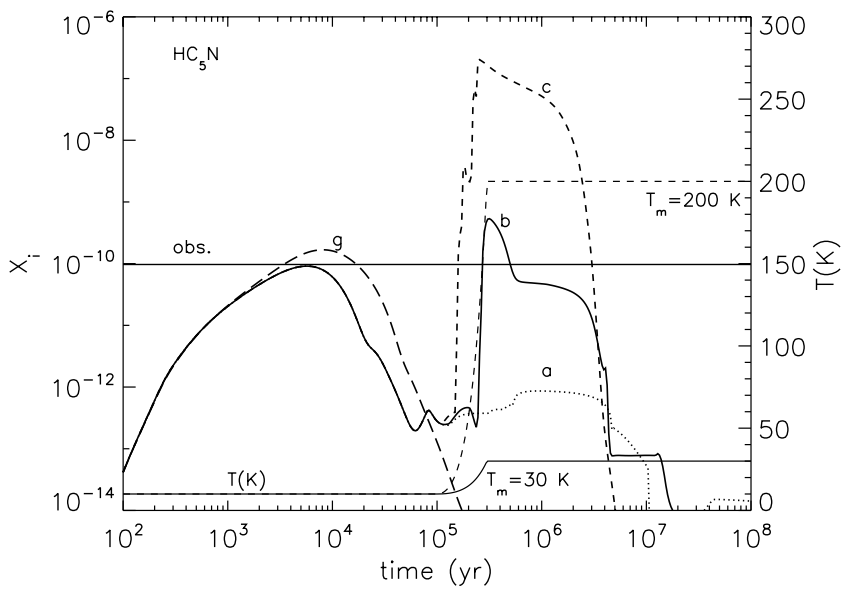

Fig. 3.- Temporal evolution of the $\mathrm{HC}_{5} \mathrm{~N}$ abundance. The labels are the same as those used for Fig. 2.

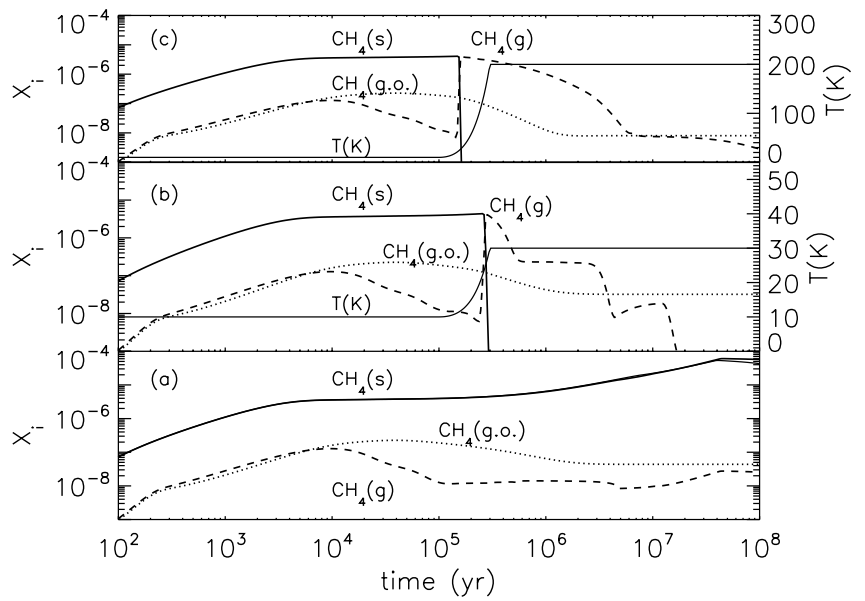

FIG. 4.-Abundance evolution of $\mathrm{CH}_{4}$ with heating. Solid lines represent $\mathrm{CH}_{4}(\mathrm{~s})$ and dashed lines represent $\mathrm{CH}_{4}(\mathrm{~g})$ in gas-grain models. For comparison, dotted lines labeled $\mathrm{CH}_{4}$ (g.o.) represent $\mathrm{CH}_{4}(\mathrm{~g})$ formed by gas-phase processes only. (a) Results for constant $T=10 \mathrm{~K} ;(b)$ warm up to $T_{\max }=30 \mathrm{~K}$, including the temperature profile; and (c) warm up to $T_{\max }=200 \mathrm{~K}$, also with a temperature profile.

without grain-surface reactions form much less methane [see the abundances of $\mathrm{CH}_{4}$ (gas only) in Fig. 4], and thus are incapable of regenerating secondary products, as can be seen for $\mathrm{C}_{4} \mathrm{H}$ and $\mathrm{HC}_{5} \mathrm{~N}$ in Figures 2 and 3 in the curves labeled g.

The regeneration of unsaturated carbon-chain molecules does not occur as simple sublimation from grain surfaces, but rather as the result of subsequent gas-phase chemistry, similar to that discussed in a dynamic model of the TMC-1 subcores by Markwick et al. (2000). For the models with $T_{\max }=30 \mathrm{~K}$ the most fundamental steps following the sublimation of methane are those leading to the formation of acetylene and related hydrocarbon ions,

$$
\begin{aligned}
& \mathrm{C}^{+}+\mathrm{CH}_{4} \longrightarrow \mathrm{C}_{2} \mathrm{H}_{3}^{+}+\mathrm{H}, \\
& \mathrm{C}^{+}+\mathrm{CH}_{4} \longrightarrow \mathrm{C}_{2} \mathrm{H}_{2}^{+}+\mathrm{H}_{2},
\end{aligned}
$$

followed by

$$
\mathrm{C}_{2} \mathrm{H}_{2}^{+}+\mathrm{H}_{2} \longrightarrow \mathrm{C}_{2} \mathrm{H}_{4}^{+},
$$

which lead to the dissociative electron recombination reactions

$$
\mathrm{C}_{2} \mathrm{H}_{3}^{+}+e^{-} \longrightarrow \mathrm{C}_{2} \mathrm{H}_{2}+\mathrm{H}
$$

and

$$
\mathrm{C}_{2} \mathrm{H}_{4}^{+}+e^{-} \longrightarrow \mathrm{C}_{2} \mathrm{H}_{2}+2 \mathrm{H} .
$$

Further reactions among the two-carbon ions and acetylene produce three- and four-carbon atom species. These products react in turn to form the longer chain $\mathrm{C}_{n} \mathrm{H}$ and $\mathrm{C}_{n} \mathrm{H}_{2}$ species. A by-product of the ion molecule network, $\mathrm{CN}$, will also react with acetylene:

$$
\mathrm{CN}+\mathrm{C}_{2} \mathrm{H}_{2} \longrightarrow \mathrm{HC}_{3} \mathrm{~N}+\mathrm{H},
$$

which is the primary formation path of the first member of the polyyne family. Further, more complex reaction pathways form longer $\mathrm{C}_{n} \mathrm{~N}$ and $\mathrm{HC}_{2 n} \mathrm{CN}$ species.

In models where the temperature increases to $100-200 \mathrm{~K}$, the unsaturated chemistry discussed here is combined with the hot-core 
TABLE 4

Observed and Peak Calculated Fractional Abundances of Assorted Hot Core/Corino Species

\begin{tabular}{|c|c|c|c|c|c|c|}
\hline Species & Observed Fractional Abundance & $T=10 \mathrm{~K}$ & $T_{\max }=30 \mathrm{~K}$ & $T_{\max }=100 \mathrm{~K}$ & $T_{\max }=200 \mathrm{~K}$ & Source \\
\hline $\mathrm{CH}_{3} \mathrm{CN}$ & $7(-07)^{\mathrm{a}}$ & $3.4(-09)$ & $1.5(-11)$ & $7.4(-08)$ & $8.3(-08)$ & $\mathrm{G} 327.3-0.6$ \\
\hline $\mathrm{CH}_{3} \mathrm{OH}$ & $\begin{array}{r}2(-05)^{\mathrm{a}} \\
\leq 7(-09)^{\mathrm{b}} \\
3(-07)^{\mathrm{d}}\end{array}$ & $\begin{array}{c}6.0(-10) \\
\ldots \\
\ldots\end{array}$ & $\begin{array}{c}6.9(-11) \\
\ldots \\
\ldots\end{array}$ & $\begin{array}{c}2.5(-07) \\
\ldots \\
\ldots\end{array}$ & $\begin{array}{c}1.2(-06) \\
\ldots \\
\ldots\end{array}$ & $\begin{array}{l}\text { G327.3-06 } \\
\text { NGC } 1333 \text { IRAS } 4 A^{c} \\
\text { IRAS } 162932422^{c}\end{array}$ \\
\hline $\mathrm{H}_{2} \mathrm{CO}$ & $\begin{array}{l}2(-08)^{\mathrm{e}} \\
1(-07)^{\mathrm{d}}\end{array}$ & $\begin{array}{c}1.2(-09) \\
\ldots\end{array}$ & $\begin{array}{c}4.3(-09) \\
\ldots\end{array}$ & $\begin{array}{c}3.8(-08) \\
\ldots\end{array}$ & $\begin{array}{c}3.7(-08) \\
\ldots\end{array}$ & $\begin{array}{l}\text { NGC } 1333 \text { IRAS } 4 A^{c} \\
\text { IRAS } 162932422^{c}\end{array}$ \\
\hline $\mathrm{HC}_{3} \mathrm{~N}$ & $\begin{array}{r}3(-11)^{\mathrm{a}} \\
1.6(-09)^{\mathrm{f}}\end{array}$ & $\begin{array}{c}3.1(-09) \\
\ldots\end{array}$ & $\begin{array}{c}8.8(-10) \\
\ldots\end{array}$ & $\begin{array}{c}1.2(-07) \\
\ldots\end{array}$ & $\begin{array}{c}1.4(-07) \\
\ldots\end{array}$ & $\begin{array}{l}\text { G327.3-0.6 } \\
\text { Orion KL }\end{array}$ \\
\hline $\mathrm{HCOOH}$ & $\begin{array}{c}{[4.6 \pm 7.9](-09)^{\mathrm{b}}} \\
6.2(-08)^{\mathrm{d}}\end{array}$ & $\begin{array}{c}1.8(-10) \\
\ldots\end{array}$ & $\begin{array}{c}6.0(-12) \\
\ldots\end{array}$ & $\begin{array}{c}5.1(-09) \\
\ldots\end{array}$ & $\begin{array}{c}1.6(-08) \\
\ldots\end{array}$ & $\begin{array}{l}\text { NGC } 1333 \text { IRAS } 4 A^{c} \\
\text { IRAS } 162932422^{c}\end{array}$ \\
\hline 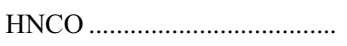 & $3(-09)^{\mathrm{a}}$ & $4.6(-09)$ & $4.5(-12)$ & $7.6(-07)$ & $8.3(-07)$ & G327.3-0.6 \\
\hline
\end{tabular}

a Gibb et al. (2000).

${ }^{\mathrm{b}}$ Bottinelli et al. (2004); [3.4 \pm 1.7$](-08)$ is the A substate of $\mathrm{HCOOCH}_{3} ;[3.6 \pm 0.7](-08)$ is the E substate of $\mathrm{HCOOCH}_{3}$.

${ }^{\mathrm{c}}$ Hot corino.

${ }^{d}$ Cazaux et al. (2003); $[1.7 \pm 0.7](-07)$ is the A substate of $\mathrm{HCOOCH}_{3} ;[2.3 \pm 0.8](-07)$ is the E substate of $\mathrm{HCOOCH}_{3}$.

e Maret et al. (2004).

${ }^{f}$ Blake et al. (1987).

chemistry discussed in Garrod \& Herbst (2006), in which a radicalbased surface chemistry followed by the desorption of less vaporizable molecules helps to produce the oxygen-rich organic molecules detected in hot cores. The observed and peak calculated abundances of some typical hot core molecules, such as $\mathrm{CH}_{3} \mathrm{OH}, \mathrm{H}_{2} \mathrm{CO}$, and $\mathrm{CH}_{3} \mathrm{CN}$ are included in Table 4, where it can be seen that the lukewarm heating is insufficient to reproduce the observations of typical hot cores.

Our warm-up models treat the desorption of surface species as if they were pure ices. In reality, mixtures of ices act in a more complex manner. The surface experiments of Collings et al. (2004) address the trapping of more volatile species, where they are either deposited as a surface layer on top of amorphous water ice or codeposited with water. The results indicate that a significant fraction of the most volatile molecules, $\mathrm{CO}, \mathrm{N}_{2}$, and $\mathrm{O}_{2}$, can be partially retained in the icy mantle to temperatures much greater than their typical sublimation temperatures. Such an effect has been considered in the hot-core models of Viti et al. (2004). Our gas-grain code currently does not model surfaces in sufficient detail to account for this retentive effect of water; however, comparison with the other molecules would indicate that not more than half of the available $\mathrm{CH}_{4}(\mathrm{~s})$ would likely be retained. The fraction released to the gas phase under these conditions still represents a tremendous enhancement over the amount of $\mathrm{CH}_{4}(\mathrm{~g})$ formed by gas phase processes only. Moreover, a gasphase model in preparation by Harada \& Herbst shows that the production of unsaturated species from methane is not strongly affected by such a diminution in the amount of gaseous methane vaporized in the vicinity of $30 \mathrm{~K}$.

\subsection{Comparison with Observations}

Figures 2 and 3 have an important contrast that helps to clarify the major question of this paper. The cold "early-time" peak of $\mathrm{C}_{4} \mathrm{H}$ is less than the observation by more than an order of magnitude, and only the warm-up models produce enough $\mathrm{C}_{4} \mathrm{H}$ to agree with the observation. However, the observed abundance of $\mathrm{HC}_{5} \mathrm{~N}$ can be fit to within an order of magnitude with warmup models or with the cold early-time peak. We therefore compare the results of all the observed species to determine whether the composition of L1527 requires heating to match the observed composition, or whether the results are ambivalent. The reaction network does not differentiate between the normal and carbene isomers of the $\mathrm{C}_{n} \mathrm{H}_{2}$ molecules, which have been detected in L1527. We assume that the observable carbene isomer $\mathrm{H}_{2} \mathrm{C}_{3}$ represents $2 \%$ of the total abundance of $\mathrm{C}_{3} \mathrm{H}_{2}$, as calculated for a dark cloud using the gas-phase network described in Park et al. (2006). We extend this estimate to the entire group of $\mathrm{C}_{n} \mathrm{H}_{2}$ species in order to compare the calculations with the abundances of isomers that were actually observed.

To formulate a quantitative answer to the cold-warm up dichotomy, we revisit the "mean confidence level" method utilized by Garrod et al. (2007). The confidence level, $\kappa_{i}$, for agreement between the computed abundance, $X_{i}$, and the observation, $X_{\mathrm{obs}, i}$, for each relevant molecule is computed as

$$
\kappa_{i}=\operatorname{erfc}\left[\frac{\left|\log \left(X_{i}\right)-\log \left(X_{\mathrm{obs}, i}\right)\right|}{\sqrt{2} \sigma}\right],
$$

where the agreement improves as $\kappa_{i}$ approaches 1 . As before, we define $\sigma=1$ so that $\kappa_{i}=0.317$ indicates a 1 order of magnitude departure from the observed value. In addition to the SS08 observations, we include the JSV04 observations to analyze the composition of the cloud. The average value $\kappa$ of the confidence level for each set of observations and for all observations combined is shown in Figure 5 as a function of time.

Within this figure, several meaningful peaks arise. Prior to the heating, the mean confidence level peaks at early time for all three data sets in the region of the cold peak. For the heated 


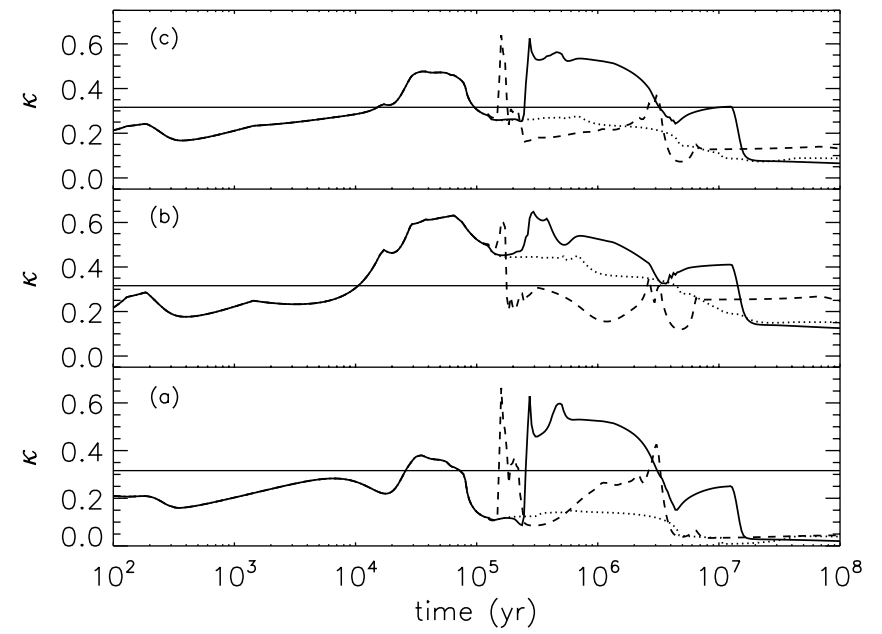

FIG. 5.-Mean confidence level $\kappa$ for observed molecules in L1527 as a function of time. (a) Results for 13 carbon-chain species observed by Sakai et al. (2008b), (b) for 9 other species observed by Jørgensen et al. (2004); and (c) for all 22 observed species. The solid line represents $T_{\max }=30 \mathrm{~K}$ models, the dashed line represents $T_{\max }=200 \mathrm{~K}$ models, and the dotted line represents cold models The horizontal line represents 1 order of magnitude average difference between observed and calculated abundances.

models, a peak appears at $t \approx 3 \times 10^{5} \mathrm{yr}$ for $T_{\max }=30 \mathrm{~K}$ and at $t \approx 1.5 \times 10^{5} \mathrm{yr}$ for $T_{\max }=200 \mathrm{~K}$. These peaks indicate that the cold models show an overall agreement within 1 order of magnitude of the observation, and that the heated models also agree with observation to a similar extent when $T \approx 30 \mathrm{~K}$. There is also a secondary peak for the $200 \mathrm{~K}$ warm-up models at higher temperatures, which indicates that abundances have increased to overly large values compared with observation as the temperature exceeds $30 \mathrm{~K}$, and then decrease once again.

Now let us compare the data sets more carefully. The bottom panel in Figure 5 displays the SS08 observations of unsaturated carbon-chain and cyanopolyyne molecules. Here it can be seen that the confidence level peaks associated with heating exceed that in the cold period. Specifically, the confidence level associated with heating is elevated to 0.628 at $t=2.7 \times 10^{5} \mathrm{yr}$ and $T=25 \mathrm{~K}$ for the $T_{\max }=30 \mathrm{~K}$ model. The peak confidence level for the $T_{\max }=200 \mathrm{~K}$ model is 0.663 at $t=1.6 \times 10^{5} \mathrm{yr}$ and $T=27 \mathrm{~K}$, indicating average agreement for heated models to within a factor of 3 . The confidence level of the cold peak is 0.380 at $t=3.5 \times 10^{4} \mathrm{yr}$, indicating agreement to within a factor of 7.5. In this set of observations, heating gives an overall better fit to the observed data. The middle panel displays the JSV04 observation set. This plot shows an ambivalence between the cold peak and the heated models, as the maximum confidence levels are 0.631 for the cold peak at $t=6.5 \times 10^{4} \mathrm{yr}, 0.648$ for $T_{\max }=30 \mathrm{~K}$ at $t=2.9 \times 10^{5} \mathrm{yr}$ and $T=29 \mathrm{~K}$, and 0.606 for $T_{\max }=200 \mathrm{~K}$ and $T=27 \mathrm{~K}$ at $t=1.6 \times 10^{5} \mathrm{yr}$, indicating agreement to within a factor of 3 for all three possibilities. The two sets of observations are combined in the top panel, where the warmed models show slightly higher confidence levels of 0.624 and 0.639 as compared with 0.476 (factor of 5) for cold processes. The optimal agreement peaks for the combined data set occur at the same times as for the SS08 observations.

This analysis marginally favors the explanation that the observed L1527 composition results at least partially from heating, although it should be noted that the very high confidence level for the warm-up peak lasts only a brief period of time $\left(\approx 10^{4} \mathrm{yr}\right)$, especially for models with higher maximum temperatures, where the postpeak drop is precipitous. The significance of dividing this
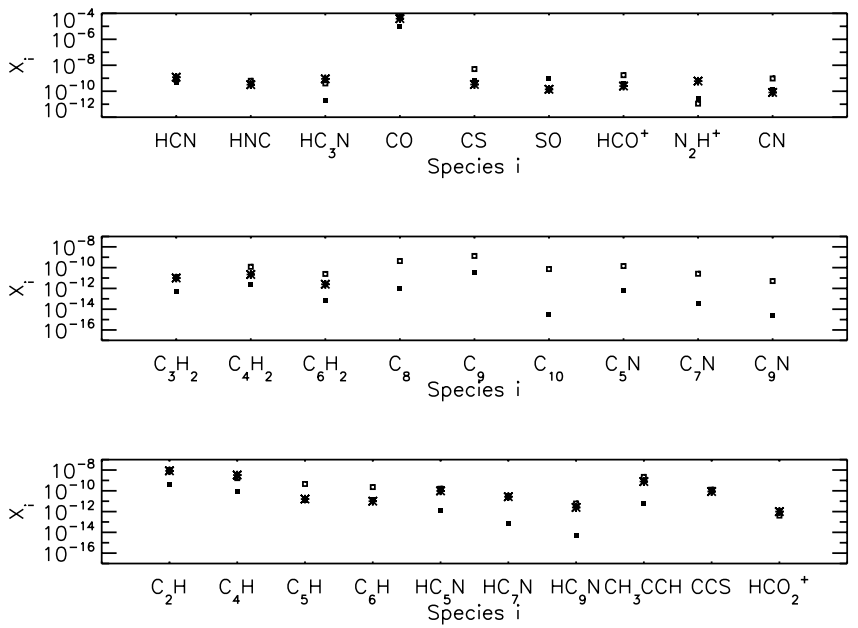

FIG. 6.-Calculated abundances of various carbon-chain and other molecules at the time of optimum agreement between models and observations for warm up to $T_{\max }=30 \mathrm{~K}$. Abundance results for $T_{\max }=30 \mathrm{~K}$ (open squares) at $t=2.7 \times 10^{5} \mathrm{yr}$ are compared with optimal cold values for constant $T=10 \mathrm{~K}$ (filled squares) at $t=3.5 \times 10^{4} \mathrm{yr}$. Observations (asterisks) are denoted where appropriate.

confidence analysis by observation set is that the SS08 results included a profile mapping procedure to demonstrate that the velocity of $\mathrm{C}_{4} \mathrm{H}$ observations is associated with the central protostar and spread throughout the gaseous envelope of L1527, rather than associated with the outflows. The JSV04 observations do not distinguish systematic velocity components. Future study of this region with detailed interferometry would certainly add more spatial abundance information and likely better resolve the dichotomy between cold and warm explanations for the composition.

Some individual molecular abundances are summarized in Figures 6 and 7 at the optimum times determined from the above analysis. Figure 6 compares the optimal warm-up results for $T_{\max }=30 \mathrm{~K}$ with the optimal cold results, whereas Figure 7 is a similar comparison for the optimal $T_{\max }=200 \mathrm{~K}$ results. The optimal cold results pertain to a cold prestellar source with density $10^{6} \mathrm{~cm}^{-3}$ and should not be confused with dark cloud abundances such as those of TMC-1. The bottom panels of these figures display the results for the SS08 species that do not require any adjustment, with the observed values denoted by asterisks
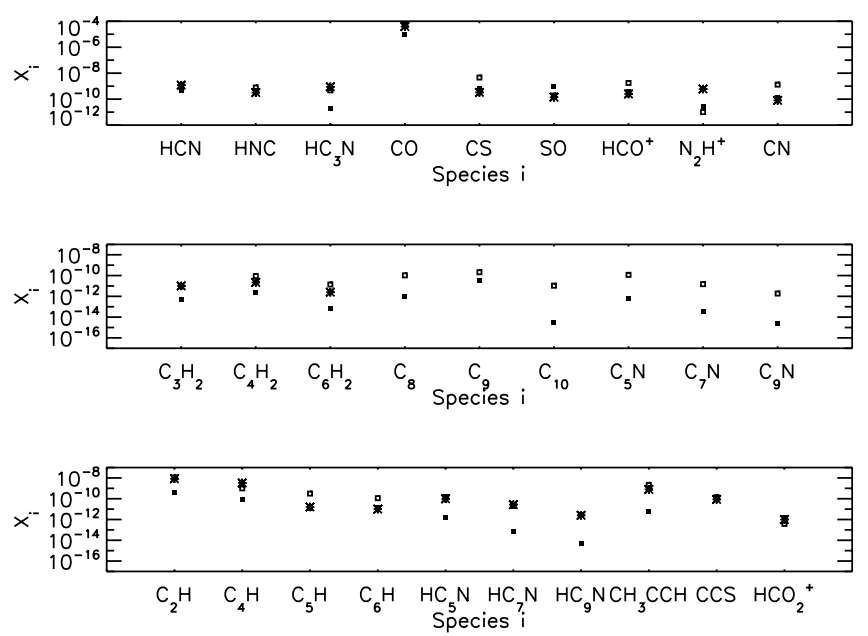

FIG. 7.- Similar results as Fig. 6, but for $t=1.6 \times 10^{5} \mathrm{yr}$, the time of optimum agreement for warm up to $T_{\max }=200 \mathrm{~K}$. 
where appropriate. The center panels include the $\mathrm{C}_{n} \mathrm{H}_{2}$ species detected by SS08 and some potentially detectable varieties of carbon-chain molecules. The top panels display the results relating to observations of JSV04. In general, these plots also indicate on a visual basis that the SS08 molecules are well reproduced by warm-up models. Optimal abundances are also listed in Table 5, which includes the observed molecules as well as a larger number of predictions. In this table, italic type indicates that the computed abundance exceeds the observed value by 1 order of magnitude or more. Boldface type indicates that the computed abundance is too small by at least 1 order of magnitude.

From Table 5, we can see the individual levels of agreement for observed species at optimum times. At the optimum time for agreement of warm-up models, a total of 17 of 22 of the observed molecules are within 1 order of magnitude of the observation, including 11 of the $13 \mathrm{SS} 08$ species and 6 of the 9 from JSV04. Variations in heating do change the optimum time but not the number of molecules in agreement. The molecules which do not agree with observation at the optimum time are $\mathrm{C}_{5} \mathrm{H}, \mathrm{C}_{6} \mathrm{H}, \mathrm{CS}$, $\mathrm{CN}$, and $\mathrm{N}_{2} \mathrm{H}^{+}$, where the models overproduce the first four, but do not make enough $\mathrm{N}_{2} \mathrm{H}^{+}$.

At the optimum time of agreement for the cold-phase model, $t=3.5 \times 10^{4} \mathrm{yr}$, only 5 of the $13 \mathrm{SS} 08$ molecules agree with observation to within an order of magnitude, while 8 of 9 JSV0 4 molecules agree, for a total of 13 out of the 22 . One reason for this comparatively worse agreement can be seen in Figures 2 and 3 , where the cold peaks arise at different times. Overall, cold processes in this model tend to underproduce the carbon chain molecules observed by SS08, and cannot produce $\mathrm{C}_{4} \mathrm{H}$ or $\mathrm{HC}_{9} \mathrm{~N}$ to within an order of magnitude of the observation at any time. The superiority of the warm-up model for carbon-chain species is seen dramatically in Figures 6 and 7. As the carbon chain molecules get longer, the abundances relative to the cold values are drastically enhanced. This effect occurs to such an extent that longer chain molecules of the classes $\mathrm{C}_{n} \mathrm{H}, \mathrm{C}_{n} \mathrm{H}_{2}$, and $\mathrm{HC}_{2 n} \mathrm{CN}$ have only slighter lower abundances than the shorter chains in that group, at least on the scale depicted here. The trend presents a good criterion for prediction of further observations of lukewarm corinos. As shown in Figure 6 of SS08, the abundances of carbon-chain species observed in L1527 tend to be slightly lower than those observed in the cold core TMC-1. These latter observations are fit by cold models in which carbon-rich elemental abundances must be used (Smith et al. 2004; Wakelam et al. 2006), or models in which nonthermal mantle evaporation occurs (Markwick et al. 2000).

Among the molecules detected in L1527, two stand out as almost uniquely abundant: $\mathrm{C}_{2} \mathrm{H}$ and $\mathrm{C}_{3} \mathrm{H}_{2}$. SS08 demonstrated that the abundance of $\mathrm{C}_{2} \mathrm{H}$ is remarkably high in comparison with several other star-forming and starless cores on the basis of a previous survey (Suzuki et al. 1992). The calculated abundance of $\mathrm{C}_{2} \mathrm{H}$ for $T_{\max }=30 \mathrm{~K}$ remains elevated at this temperature at nearly 1 order of magnitude greater than the cold peak value for several million years. However, the abundance of the $T_{\max }=$ $200 \mathrm{~K}$ model peaks and then rapidly declines to the level of the cold value as $T$ approaches $100 \mathrm{~K}$, prior to $t=2 \times 10^{5} \mathrm{yr}$. This unusual result explains that $\mathrm{L} 1527$ at $T \approx 30 \mathrm{~K}$ can reasonably have $\mathrm{C}_{2} \mathrm{H}$ abundance that is nearly an order of magnitude greater than both colder starless cores and hotter star forming regions. This finding is in agreement with the $\mathrm{C}_{2} \mathrm{H}$ image of Beuther et al. (2008) for IRAS 18089-1732, which shows a hole toward the hot core.

In addition, Benson et al. (1998) indicated that the abundance of $\mathrm{C}_{3} \mathrm{H}_{2}$ was remarkably greater toward $\mathrm{L} 1527$ and the TMC-1 subcores than toward any other cold sources included in their survey. Our calculated lukewarm abundance of $\mathrm{C}_{3} \mathrm{H}_{2}$ increases by an order of magnitude over the cold abundance and remains elevated for a long period of time. The high abundances of both $\mathrm{C}_{2} \mathrm{H}$ and $\mathrm{C}_{3} \mathrm{H}_{2}$ lend support to the explanation that partial mantle removal in L1527 results in systematic enhancements in carbonchain abundances, although the case is less obvious for TMC-1 (Wakelam et al. 2006; Markwick et al. 2000).

\subsection{Observational Predictions}

The peak abundance values for a variety of carbon-chain and other molecules for $T_{\max }=30 \mathrm{~K}$ are listed in Table 3, while the abundances at the optimal times for L1527 are listed in Table 5 for all warm-up models. This information provides observational predictions for L1527, as well as any other potential lukewarm corino sources.

While our model calculations indicate that warming can successfully regenerate carbon-chain species, they also introduce an unexpected result for hot-core and hot-corino chemistry. Heating to $T_{\max }=200 \mathrm{~K}$ increases the peak abundances of these molecules by at least an order of magnitude above the $T_{\max }=30 \mathrm{~K}$ peak (see Table 3). Moreover, except for the species $\mathrm{C}_{2} \mathrm{H}$ (see above), these high abundances do not decline rapidly. Previously, carbon-chain species have not been reported in hot core/ corino observations, with the exception of $\mathrm{HC}_{3} \mathrm{~N}$ (Wyrowski et al. 1999; Gibb et al. 2000; Blake et al. 1987), to the best of our knowledge. It is not clear whether unsaturated chain hydrocarbons are simply not present in the observed hot cores, or whether they are not detected in the complex spectra of these regions, which are typically dominated by so-called weeds. However, in a recent survey of the hot corino source IRAS $16293+2422$, a number of small carbon-chain species have been detected and are likely to exist in the warm region of the source (E. Caux 2007, private communication; C. Ceccarelli 2007, private communication). This survey lends a degree of support to our model result of enhanced carbon-chain abundance in hot regions. However, it is also possible that the high abundances we predict in hot cores may be the result of a lack of destruction mechanisms that become important at higher temperatures.

\subsection{Increased Sulfur}

The gas-phase elemental abundance of sulfur in cold dense sources is highly uncertain because there is no evidence for depletion in diffuse clouds, yet use of a high value for cold dense sources tends to worsen agreement with observations (Quan et al. 2008). If the sulfur abundance in our model is raised to $1 \times 10^{-5}$ (see Table 2), certain results are affected much more strongly than others. For the cold phase, the major changes are large diminutions in the peak abundances of the $\mathrm{C}_{n} \mathrm{H}$ species and an increase of at least an order of magnitude for the sulfur-bearing species such as CCS. For the warm-up phase of the $T_{\max }=30 \mathrm{~K}$ model to lukewarm corino conditions, the results change little, with peak abundances for all species listed in our tables altered at most by a factor of 3 . For the $T_{\max }=100 \mathrm{~K}$ and $T_{\max }=200 \mathrm{~K}$ models, the peak abundances tend to be reduced for the carbonchain species, and their postpeak declines tend to occur more quickly, at a timescale of at most $10^{6} \mathrm{yr}$, reducing the possible discrepancy with observation for carbon-chain species in hot cores of this age.

With the mean confidence level approach, we see that the optimum $\kappa$ for the observed species in the cold era decreases to 0.350 , barely corresponding to order-of-magnitude agreement. The optimum $\kappa$ for the warm-up models does not change significantly, 
TABLE 5

Observed and Optimal Time Fractional Abundances

\begin{tabular}{|c|c|c|c|c|c|}
\hline Species & Observed Fractional Abundance ${ }^{a}$ & $T_{\max }=10 \mathrm{~K}$ & $T_{\max }=30 \mathrm{~K}$ & $T_{\max }=100 \mathrm{~K}$ & $T_{\max }=200 \mathrm{~K}$ \\
\hline $\mathrm{C}_{2} \mathrm{H} \ldots \ldots \ldots \ldots \ldots \ldots \ldots \ldots \ldots \ldots \ldots \ldots \ldots \ldots \ldots \ldots \ldots$ & $8.3(-09)$ & $3.9(-10)$ & $8.9(-09)$ & $1.0(-08)$ & $1.1(-08)$ \\
\hline $\mathrm{C}_{3} \mathrm{H} \ldots \ldots \ldots \ldots \ldots \ldots \ldots \ldots \ldots \ldots \ldots \ldots \ldots \ldots \ldots \ldots \ldots$ & $\ldots$ & $4.9(-10)$ & $1.0(-09)$ & $8.6(-10)$ & $8.4(-10)$ \\
\hline 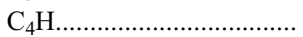 & $3.3(-09)$ & $8.2(-11)^{b}$ & $1.7(-09)$ & $1.1(-09)$ & $9.9(-10)$ \\
\hline $\mathrm{C}_{5} \mathrm{H}$ & $1.6(-11)$ & $1.2(-11)$ & $4.6(-10)^{\mathrm{c}}$ & $3.3(-10)$ & $3.1(-10)$ \\
\hline $\mathrm{C}_{6} \mathrm{H}$ & $1.0(-11)$ & $1.3(-11)$ & $2.3(-10)$ & $1.3(-10)$ & $1.1(-10)$ \\
\hline 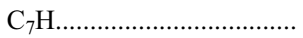 & $\ldots$ & $7.7(-13)$ & $1.3(-10)$ & $6.9(-11)$ & $6.1(-11)$ \\
\hline $\mathrm{C}_{8} \mathrm{H}$ & $\ldots$ & $5.9(-13)$ & $1.1(-10)$ & $4.5(-11)$ & $3.6(-11)$ \\
\hline $\mathrm{C}_{9} \mathrm{H}$ & $\ldots$ & $4.1(-14)$ & $7.2(-11)$ & $2.9(-11)$ & $2.3(-11)$ \\
\hline $\mathrm{HC}_{5} \mathrm{~N}$ & $9.7(-11)$ & $1.4(-12)$ & $1.6(-10)$ & $1.4(-10)$ & $1.5(-10)$ \\
\hline $\mathrm{HC}_{7} \mathrm{~N} \ldots \ldots \ldots \ldots \ldots \ldots \ldots$ & $2.7(-11)$ & $7.5(-14)$ & $2.9(-11)$ & $2.1(-11)$ & $2.0(-11)$ \\
\hline $\mathrm{HC}_{9} \mathrm{~N} \ldots \ldots \ldots \ldots \ldots \ldots$ & $2.5(-12)$ & $5.0(-15)$ & $5.9(-12)$ & $3.0(-12)$ & $2.7(-12)$ \\
\hline $\mathrm{C}_{2} \mathrm{H}_{2} \ldots \ldots \ldots \ldots \ldots \ldots$ & $\ldots$ & $6.5(-09)$ & $3.7(-08)$ & $3.3(-08)$ & $3.2(-08)$ \\
\hline $\mathrm{C}_{3} \mathrm{H}_{2} \ldots \ldots \ldots \ldots \ldots \ldots \ldots \ldots \ldots \ldots \ldots \ldots$ & $1.0(-11)$ & $5.0(-13)$ & $1.1(-11)$ & $9.6(-12)$ & $9.3(-12)$ \\
\hline $\mathrm{C}_{4} \mathrm{H}_{2} \ldots \ldots \ldots \ldots \ldots \ldots \ldots \ldots \ldots \ldots \ldots \ldots \ldots \ldots$ & $2.2(-11)$ & $2.4(-12)$ & $1.2(-10)$ & $9.6(-11)$ & $9.0(-11)$ \\
\hline $\mathrm{C}_{6} \mathrm{H}_{2} \ldots \ldots \ldots \ldots \ldots \ldots \ldots \ldots \ldots \ldots \ldots \ldots \ldots \ldots$ & $2.5(-12)$ & $6.3(-14)$ & $2.5(-11)$ & $1.5(-11)$ & $1.4(-11)$ \\
\hline $\mathrm{C}_{7} \mathrm{H}_{2} \ldots \ldots \ldots \ldots \ldots \ldots \ldots \ldots \ldots \ldots \ldots \ldots \ldots$ & $\ldots$ & $9.8(-15)$ & $7.1(-12)$ & $4.0(-12)$ & $3.4(-12)$ \\
\hline $\mathrm{C}_{8} \mathrm{H}_{2} \ldots \ldots \ldots \ldots \ldots \ldots \ldots \ldots \ldots \ldots \ldots \ldots \ldots \ldots \ldots$ & $\ldots$ & $7.1(-15)$ & $5.6(-12)$ & $2.6(-12)$ & $2.1(-12)$ \\
\hline $\mathrm{C}_{9} \mathrm{H}_{2} \ldots \ldots \ldots \ldots \ldots \ldots \ldots$ & $\ldots$ & $5.5(-16)$ & $2.6(-12)$ & $1.0(-12)$ & $7.8(-13)$ \\
\hline $\mathrm{CH}_{3} \mathrm{CCH}$ & $7.8(-10)$ & $5.9(-12)$ & $2.2(-09)$ & $2.1(-09)$ & $2.2(-09)$ \\
\hline $\mathrm{CH}_{3} \mathrm{C}_{4} \mathrm{H} \ldots \ldots \ldots \ldots \ldots \ldots \ldots \ldots \ldots \ldots \ldots \ldots$ & $\ldots$ & $1.7(-12)$ & $1.1(-09)$ & $7.0(-10)$ & $6.2(-10)$ \\
\hline $\mathrm{CH}_{3} \mathrm{C}_{6} \mathrm{H} \ldots \ldots \ldots \ldots \ldots \ldots \ldots \ldots \ldots \ldots \ldots$ & $\ldots$ & $3.1(-13)$ & $1.7(-10)$ & $8.6(-11)$ & $6.8(-11)$ \\
\hline 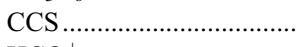 & $8.5(-11)$ & $8.2(-11)$ & $1.3(-10)$ & $1.4(-10)$ & $1.4(-10)$ \\
\hline $\mathrm{HCO}_{2}^{+} \ldots \ldots \ldots \ldots \ldots \ldots \ldots \ldots$ & $1.0(-12)$ & $1.4(-12)$ & $4.1(-13)$ & $3.8(-13)$ & $3.7(-13)$ \\
\hline $\mathrm{HCN}$ & $1.2(-09)$ & $4.6(-10)$ & $7.7(-10)$ & $8.3(-10)$ & $9.3(-10)$ \\
\hline 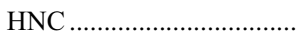 & $3.2(-10)$ & $3.9(-10)$ & $6.3(-10)$ & $7.0(-10)$ & $7.8(-10)$ \\
\hline $\mathrm{HC}_{3} \mathrm{~N}$ & $8.9(-10)$ & $2.0(-11)$ & $4.0(-10)$ & $4.3(-10)$ & $4.7(-10)$ \\
\hline 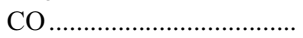 & $3.9(-05)$ & $8.9(-06)$ & $5.1(-05)$ & $5.4(-05)$ & $5.4(-05)$ \\
\hline 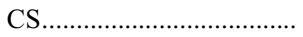 & $3.3(-10)$ & $6.4(-10)$ & $5.1(-09)$ & $5.1(-09)$ & $4.6(-09)$ \\
\hline SO & $1.4(-10)$ & $9.0(-10)$ & $1.3(-10)$ & $2.1(-10)$ & $1.9(-10)$ \\
\hline $\mathrm{CN}$ & $8.0(-11)$ & $1.4(-10)$ & $9.6(-10)$ & $1.2(-09)$ & $1.3(-09)$ \\
\hline $\mathrm{C}_{2}$ & $\ldots$ & $2.0(-10)$ & $1.1(-09)$ & $1.1(-09)$ & $1.1(-09)$ \\
\hline 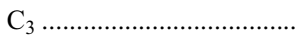 & $\ldots$ & $1.5(-07)$ & $1.1(-08)$ & $7.4(-09)$ & $6.1(-09)$ \\
\hline $\mathrm{C}_{4}$ & $\ldots$ & $2.8(-11)$ & $1.0(-09)$ & $8.2(-10)$ & $6.9(-10)$ \\
\hline 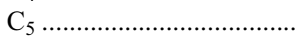 & $\ldots$ & $1.3(-08)$ & $6.7(-09)$ & $3.7(-09)$ & $2.7(-09)$ \\
\hline $\mathrm{C}_{6}$ & $\ldots$ & $2.1(-11)$ & $1.1(-09)$ & $5.8(-10)$ & $4.4(-10)$ \\
\hline $\mathrm{C}_{7}$ & $\ldots$ & $6.0(-10)$ & $2.7(-09)$ & $1.1(-09)$ & $7.4(-10)$ \\
\hline 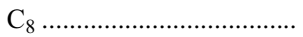 & $\ldots$ & $9.7(-13)$ & $4.3(-10)$ & $1.5(-10)$ & $1.1(-10)$ \\
\hline $\mathrm{C}_{9}$ & $\ldots$ & $3.4(-11)$ & $1.3(-09)$ & $3.5(-10)$ & $2.1(-10)$ \\
\hline 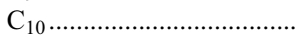 & $\ldots$ & $3.2(-15)$ & $7.3(-11)$ & $1.8(-11)$ & $1.1(-11)$ \\
\hline $\mathrm{C}_{2} \mathrm{~N} \ldots \ldots \ldots \ldots \ldots \ldots \ldots \ldots \ldots \ldots \ldots \ldots \ldots \ldots \ldots \ldots \ldots$ & $\ldots$ & $9.9(-11)$ & $4.3(-10)$ & $4.0(-10)$ & $3.9(-10)$ \\
\hline $\mathrm{C}_{3} \mathrm{~N}$ & $\ldots$ & $1.9(-11)$ & $1.2(-10)$ & $1.2(-10)$ & $1.4(-10)$ \\
\hline 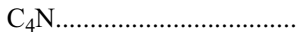 & $\ldots$ & $9.9(-12)$ & $1.7(-10)$ & $8.2(-11)$ & $6.3(-11)$ \\
\hline 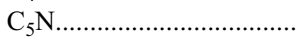 & $\ldots$ & $5.9(-13)$ & $1.4(-10)$ & $1.2(-10)$ & $1.2(-10)$ \\
\hline 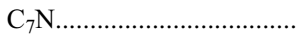 & $\ldots$ & $3.8(-14)$ & $2.6(-11)$ & $1.6(-11)$ & $1.5(-11)$ \\
\hline 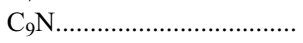 & $\ldots$ & $2.2(-15)$ & $5.1(-12)$ & $1.2(-12)$ & $1.9(-12)$ \\
\hline $\mathrm{CH}_{3} \mathrm{C}_{3} \mathrm{~N} \ldots \ldots \ldots \ldots \ldots \ldots \ldots \ldots \ldots \ldots \ldots$ & $\ldots$ & $1.9(-14)$ & $2.9(-13)$ & $2.7(-13)$ & $2.7(-13)$ \\
\hline $\mathrm{CH}_{3} \mathrm{C}_{5} \mathrm{~N} \ldots \ldots \ldots \ldots \ldots \ldots \ldots \ldots \ldots \ldots \ldots \ldots \ldots \ldots \ldots$ & $\ldots$ & $1.7(-16)$ & $2.3(-14)$ & $1.9(-14)$ & $1.8(-14)$ \\
\hline $\mathrm{CH}_{3} \mathrm{C}_{7} \mathrm{~N} \ldots \ldots \ldots \ldots \ldots \ldots \ldots$ & $\ldots$ & $8.0(-18)$ & $3.8(-15)$ & $2.3(-15)$ & $2.2(-15)$ \\
\hline $\mathrm{N}_{2} \ldots \ldots \ldots \ldots \ldots \ldots \ldots \ldots \ldots \ldots \ldots \ldots \ldots \ldots \ldots$ & $\ldots$ & $7.6(-07)$ & $5.6(-06)$ & $5.7(-06)$ & $5.7(-06)$ \\
\hline 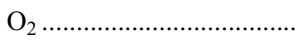 & $\ldots$ & $3.6(-07)$ & $1.1(-08)$ & $5.1(-09)$ & $4.6(-09)$ \\
\hline $\mathrm{CO}_{2} \ldots \ldots \ldots \ldots \ldots \ldots \ldots$ & $\ldots$ & $1.7(-07)$ & $4.1(-09)$ & $2.8(-09)$ & $2.4(-09)$ \\
\hline $\mathrm{C}_{3} \mathrm{H}_{3} \ldots \ldots \ldots \ldots \ldots \ldots$ & $\ldots$ & $2.3(-12)$ & $2.2(-09)$ & $2.2(-09)$ & $2.3(-09)$ \\
\hline 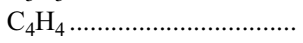 & $\ldots$ & $4.1(-12)$ & $9.5(-11)$ & $7.8(-11)$ & $8.5(-11)$ \\
\hline $\mathrm{C}_{6} \mathrm{H}_{6} \ldots \ldots \ldots \ldots \ldots \ldots \ldots \ldots \ldots \ldots \ldots \ldots \ldots$ & $\ldots$ & $3.0(-13)$ & $3.2(-10)$ & $1.8(-10)$ & $1.7(-10)$ \\
\hline $\mathrm{H}_{2} \mathrm{CS}$ & $\ldots$ & $4.4(-11)$ & $5.2(-10)$ & $6.6(-10)$ & $7.3(-10)$ \\
\hline $\mathrm{H}_{2} \mathrm{~S}$ & $\ldots$ & $1.1(-10)$ & $3.3(-09)$ & $7.8(-09)$ & $7.7(-09)$ \\
\hline $\mathrm{CH}_{2} \mathrm{CN} \ldots \ldots \ldots \ldots \ldots \ldots \ldots$ & $\ldots$ & $2.7(-11)$ & $7.4(-11)$ & $8.6(-11)$ & $8.6(-11)$ \\
\hline $\mathrm{CH}_{2} \mathrm{CO} \ldots \ldots \ldots \ldots \ldots \ldots \ldots \ldots$ & $\ldots$ & $2.7(-10)$ & $1.0(-09)$ & $1.2(-09)$ & $1.1(-09)$ \\
\hline
\end{tabular}


TABLE 5-Continued

\begin{tabular}{|c|c|c|c|c|c|}
\hline Species & Observed Fractional Abundance & $T_{\max }=10 \mathrm{~K}$ & $T_{\max }=30 \mathrm{~K}$ & $T_{\max }=100 \mathrm{~K}$ & $T_{\max }=200 \mathrm{~K}$ \\
\hline $\mathrm{CH}_{3} \mathrm{OCH}_{3} \ldots \ldots \ldots \ldots \ldots \ldots$ & $\ldots$ & $1.4(-17)$ & $3.8(-16)$ & $1.1(-17)$ & $6.9(-18)$ \\
\hline $\mathrm{H}_{2} \mathrm{CO} \ldots \ldots \ldots \ldots \ldots \ldots$ & $\ldots$ & $5.9(-11)$ & $4.3(-09)$ & $4.3(-09)$ & $4.5(-09)$ \\
\hline $\mathrm{HCOOH}$ & $\ldots$ & $6.1(-11)$ & $3.6(-12)$ & $1.7(-12)$ & $1.5(-12)$ \\
\hline $\mathrm{HCOOCH}_{3} \ldots \ldots \ldots \ldots \ldots$ & $\ldots$ & $2.4(-16)$ & $3.8(-15)$ & $5.9(-16)$ & $4.7(-16)$ \\
\hline HNCO & $\ldots$ & $2.2(-10)$ & $2.4(-12)$ & $4.3(-12)$ & $4.2(-12)$ \\
\hline
\end{tabular}

a Observational references are the same as those in Table 3.

b Boldface type indicates that the computed abundance is less than the observed value by 1 order of magnitude or more.

c Italic type indicates that the computed abundance is greater than the observed value by 1 order of magnitude or more.

on the other hand, indicating a stronger preference for lukewarm processes than in the low-sulfur case.

\section{CONCLUSIONS}

Using our gas-grain chemical model, we have attempted to distinguish the chemical composition of L1527 from more familiar evolutionary phases. More specifically, this composition poses the dilemma that the observed gas-phase abundances might have required heating, might be explained by cold processes alone, or might require a combination of the two depending on exactly where the molecules are located within the source. We have approached this question by computing a series of one-point model simulations of a dense core that include various degrees of heating after a preliminary cold phase lasting $10^{5} \mathrm{yr}$. A mean confidence level analysis indicates that the composition of the cloud is somewhat more likely to be a result of heating and regeneration than of cold processes. Dividing the observed molecules into two classes - the carbon-chain species detected by SS08 and the species detected by JSV04-we find that the preference for a warm-up model is stronger for the former species, although the level of high agreement during the warm-up period is brief. This preference is strengthened by the use of a high value for the sulfur elemental abundance.

The best agreement between model and observation occurs as the most volatile molecules are being desorbed from the grain surfaces. This agreement occurs at $t=2.7 \times 10^{5} \mathrm{yr}$ and $T=25 \mathrm{~K}$ for the $T_{\max }=30 \mathrm{~K}$ model and $t=1.6 \times 10^{5} \mathrm{yr}$ and $T=27 \mathrm{~K}$ for the $T_{\max }=200 \mathrm{~K}$ model. Of the volatile species, the most important chemically is $\mathrm{CH}_{4}$ because it acts as a precursor for a gas-phase chemistry leading to carbon-chain species, as discussed by SS08. The distinctly large abundances of $\mathrm{C}_{2} \mathrm{H}(\mathrm{SS} 08)$ and $\mathrm{C}_{3} \mathrm{H}_{2}$ (Benson et al. 1998) as compared with various other sources provide some additional support for this lukewarm explanation of the L1527 composition. Further, the gradual dropoff in abundance of carbon-chain molecules in L1527 with increasing size is fit better with our warm up than our cold model. It should be noted, however, that our model here uses oxygen-rich elemental abundances, and that such models cannot reproduce the abundances of complex molecules seen in TMC-1, so they may underestimate the extent of molecular complexity under cold conditions in L1527 (Wakelam et al. 2006). Although the envelope of $\mathrm{L} 1527$ at $30 \mathrm{~K}$ is warmer than a cold core at $10 \mathrm{~K}$, it is not nearly as hot as a hot core or hot corino. The chemistry is clearly distinguishable from the more evolved phase, because the temperature is not high enough to release some products of grain-surface chemistry such as $\mathrm{CH}_{3} \mathrm{OH}$. If L1527 is typical of a borderline Class 0/I low-mass protostar, then the lukewarm corino phase could be fairly common. Observations of L483 show similar evolutionary characteristics, including an enhanced dust temperature of $T_{d}=40 \mathrm{~K}$ ( Tafalla et al. 2000); thus, this source may be a good candidate for a molecular survey of warm carbon chain chemistry.

One complication that arises is that the models in which the temperature rises to 100 or $200 \mathrm{~K}$ produce large abundances of most gaseous carbon-chain species in addition to the standard hot-core species and these abundances linger on timescales of $(2-5) \times 10^{6}$ yr after enhancement, unless a high elemental abundance for sulfur is utilized. The most salient exception to this rule is $\mathrm{C}_{2} \mathrm{H}$, for which we predict a low abundance in hot cores and corinos. The problem of high carbon-chain abundances in hot cores also occurs in the hydrodynamic model of Aikawa et al. (2008), in which large abundances of these species are maintained as the gas collapses to the central star and warms up. The peak results from Table 3 show that these abundances are somewhat lower than abundances for previously reported hot-core molecules (see Table 4), but may be large enough to be detectable unless their widely spaced spectral lines are hidden by those of weeds. Unfortunately, only detections of $\mathrm{HC}_{3} \mathrm{~N}$ toward hot cores have previously been reported in the literature (Wyrowski et al. 1999; Blake et al. 1987; Gibb et al. 2000). Some of these detections are sufficiently strong that one wonders why more complex cyanopolyynes have not yet been detected. Low upper limits toward Orion have been reported to us by several investigators, but this source is complex and may not be representative. A report of a recent survey in progress (E. Caux 2007, private communication) indicates, on the other hand, that some smaller carbon-chain species are indeed observable in the hot corino IRAS $16293+2422$, most likely associated with the warm region of the source. Further observations of carbon-chain molecules, particularly with lengths of four or more carbon atoms, toward additional hot core or corino sources might strengthen our characterization of L1527.

E. H. would like to thank the National Science Foundation for supporting his research program in astrochemistry and NASA for support to study interstellar ice formation. R. T. G. thanks the Alexander von Humboldt Foundation for a research fellowship.

\section{REFERENCES}

Agúndez, M., Cernicharo, J., Guélin, M., Gerin, M., McCarthy, M. C., \& Thaddeus, P. 2008, A\&A, 478, L19

Aikawa, Y., Wakelam, V., Garrod, R. T., \& Herbst, E. 2008, ApJ, 674, 984

André, P., Ward-Thompson, D., \& Barsony, M. 2000, in Protostars and Planets IV, ed. V. Mannings, A. P. Boss, \& S. S. Russell (Tucson: Univ. Arizona Press), 59
Benson, P. J., Caselli, P., \& Myers, P. C. 1998, ApJ, 506, 743

Beuther, H., Semenov, D., Henning, Th., \& Linz, H. 2008, ApJ, 675, L33

Blake, G. A., Sutton, E. C., Masson, C. R., \& Phillips, T. G. 1987, ApJ, 315, 621

Bottinelli, S., Ceccarelli, C., Neri, R., Williams, J. P., Caux, E., Cazaux, S., Lefloch, B., Maret, S., \& Tielens, A. G. G. M. 2004, ApJ, 617, L69 
Cazaux, S., Tielens, A. G. G. M., Ceccarelli, C., Castets, A., Wakelam, V., Caux, E., Parise, B., \& Teyssier, D. 2003, ApJ, 593, L51

Ceccarelli, C., Castets, A., Caux, E., Hollenbach, D., Loinard, L., Molinari, S., \& Tielens, A. G. G. M. 2000, A\&A, 355, 1129

Collings, M. P., Anderson, M. A., Chen, R., Dever, J. W., Viti, S., Williams, D. A., \& McCoustra, M. R. S. 2004, MNRAS, 354, 1133

Garrod, R. T., \& Herbst, E. 2006, A\&A, 457, 927

Garrod, R. T., Park, I. H., Caselli, P., \& Herbst, E. 2006, Faraday Discuss., 133, 51

Garrod, R. T., Wakelam, V., \& Herbst, E. 2007, A\&A, 467, 1103

Gibb, E. L., Nummelin, A., Irvine, W. M., Whittet, D. C. B., \& Bergman, P. 2000, ApJ, 545, 309

Gibb, E. L., Whittet, D. C. B., Boogert, A. C. A., \& Tielens, A. G. G. M. 2004, ApJS, 151, 35

Hasegawa, T. I., Herbst, E., \& Leung, C. M. 1992, ApJS, 82, 167

Hirota, T., Maezawa, H., \& Yamamoto, S. 2004, ApJ, 617, 399

Hogerheijde, M. R., \& Sandell, G. 2000, ApJ, 534, 880

Jørgensen, J. K., Schöier, F. L., \& van Dishoeck, E. F. 2002, A\&A, 389, 908 2004, A\&A, 416, 603 (JSV04)

Loinard, L., Rodríguez, L., D’Alessio, P., Wilner, D. J., \& Ho, P. T. P. 2002, ApJ, 581, L109

Maret, S., et al. 2004, A\&A, 416, 577

Markwick, A. J., Millar, T. J., \& Charnley, S. B. 2000, ApJ, 535, 256

Myers, P. C., \& Mardones, D. 1998, in ASP Conf. Ser. 132, Star Formation with the Infrared Space Observatory, ed. J. Yun \& R. Liseau (San Francisco: ASP), 173
Öberg, K. I., Boogert, A. C. A., Pontoppidan, K. M., Blake, G. A., Evans, N. J., Lahuis, F., \& van Dishoeck, E. F. 2008, ApJ, 678, 1032

Öberg, K. I., Fuchs, G. W., Awad, Z., Fraser, H. J., Schlemmer, S., van Dishoeck, E. F., \& Linnartz, H. 2007, ApJ, 662, L23

Ohashi, N., Hayashi, M., Ho, P. T. P., \& Momose, M. 1997, ApJ, 475, 211

Park, I. H., Wakelam, V., \& Herbst, E. 2006, A\&A, 449, 631

Quan, D., Herbst, E., Millar, T. J., Hassel, G. E., Ling, S. Y., Guo, H., Honvault, P., \& Xie, D. 2008, ApJ, in press

Sakai, N., Sakai, T., Aikawa, Y., \& Yamamoto, S. 2008a, ApJ, 675, L89

Sakai, N., Sakai, T., Hirota, T., \& Yamamoto, S. 2008b, ApJ, 672, 371 (SS08)

Sakai, N., Sakai, T., Osamura, Y., \& Yamamoto, S. 2007, ApJ, 667, L65

Sakai, N, Sakai, T., \& Yamamoto, S. 2008c, ApJ, 673, L71

Shu, F. H. 1977, ApJ, 214, 488

Smith, I. W. M., Herbst, E., \& Chang, Q. 2004, MNRAS, 350, 323

Suzuki, H., Yamamoto, S., Ohishi, M., Kaifu, N., Ishikawa, S., Hirahara, Y., \& Takano, S. 1992, ApJ, 392, 551

Tafalla, M., Myers, P. C., Mardones, D., \& Bachiller, R. 2000, A\&A, 359, 967

Viti, S., Collings, M. P., Dever, J. D., McCoustra, M. R. S., \& Williams, D. A. 2004, MNRAS, 354, 1141

Wakelam, V., Herbst, E., \& Selsis, F. 2006, A\&A, 451, 551

Wyrowski, F., Schilke, P., \& Walmsley, C. M. 1999, A\&A, 341, 882 